\title{
Pediatric acute respiratory distress syndrome: How to protect the lungs during mechanical ventilation?
}

\author{
Álvaro Coronado-Muñoz ${ }^{1,2 *}$ and Raffo Escalante-Kanashiro ${ }^{3,4}$ \\ ${ }^{1}$ Department of Pediatrics, University of Texas Health Science Center, Houston, Texas, USA; ${ }^{2}$ Pediatric Critical Care, Children's Memorial Hermann \\ Hospital, Houston, Texas, USA; ${ }^{3}$ Departamento de Emergencias y Áreas Críticas, Unidad de Cuidados Intensivos, Instituto Nacional de Salud del \\ Niño, Lima, Peru; ${ }^{4}$ Escuela de Medicina, Universidad Peruana de Ciencias Aplicadas, Lima, Peru
}

\begin{abstract}
Pediatric acute respiratory distress syndrome (PARDS) is a frequent diagnosis in critical care. This inflammatory process has different stages characterized by mild-to-severe hypoxia, and the management will vary according to the severity. New definitions for pediatric patients were published in 2015; new epidemiological evidence revising those definitions has helped understand the mortality associated with PARDS and the impact on ventilation. The strategies to protect the lungs during mechanical ventilation have been successful in reducing mortality and complications. In clinical situations where high levels of critical support are limited, other therapies with a lower level of evidence can be attempted to gain time without worsening the ongoing pulmonary injury. We offer a complete narrative revision of this syndrome, with the critical management of these patients as a priority.
\end{abstract}

Key words: Artificial respiration/methods. Respiratory distress syndrome. Adult. Prone position. Acute lung injury. Pediatrics.

\section{Síndrome de dificultad respiratoria aguda pediátrica: ¿cómo proteger los pulmones durante la ventilación mecánica?}

\section{Resumen}

El síndrome de dificultad respiratoria aguda pediátrica (SDRAP) es un diagnóstico frecuente en cuidados intensivos. Este proceso inflamatorio se caracteriza por diferentes grados de hipoxia, de leve a grave, y el manejo varía de acuerdo con la gravedad. En 2015 se publicaron nuevas definiciones para pacientes pediátricos, así como nueva evidencia epidemiológica, que toma como punto de partida dichas definiciones, lo cual ha ayudado a entender la mortalidad asociada y el impacto del manejo ventilatorio con respecto a la morbilidad en este síndrome. Las estrategias que protegen los pulmones durante la ventilación mecánica han sido exitosas en reducir la mortalidad y las complicaciones subsecuentes. En situaciones en las que existen limitaciones que impiden suministrar altos niveles de soporte crítico se pueden implementar otras medidas de menor evidencia para ganar tiempo e impedir que se extiendan las lesiones pulmonares. A continuación, se ofrece una revisión narrativa completa de este síndrome, con un enfoque que prioriza el manejo crítico de estos pacientes.

Palabras clave: Respiración artificial, métodos. Síndrome de dificultad respiratoria aguda. Adulto. Posición prono. Lesión pulmonar aguda. Pediatría.

Correspondence:

*Álvaro Coronado-Muñoz

E-mail: Alvaro.j.coronadomunoz@ uth.tmc.edu

1665-1146/@ 2020 Hospital Infantil de México Fed (http://creativecommons.org/licenses/by-nc-nd/4.0/).
Date of reception: 08-06-2020

Date of acceptance: $27-08-2020$

DOI: 10.24875/BMHIM.20000148
Available online: 08-06-2021

Bol Med Hosp Infant Mex. 2021;78(3):181-190

www.bmhim.com 


\section{Introduction}

Pediatric acute respiratory distress syndrome (PARDS) is one of the most severe problems managed in pediatric critical care units. The presence of pulmonary inflammation with compromised oxygenation is an unmistakable sign of this syndrome, which requires comprehensive and multidisciplinary management. The present article displays a narrative review, emphasizing the management of this condition (Fig. 1).

The literature search has been exhaustive in different search engines, including PubMed, EMBASE, and SciELO. Articles in English, Spanish, French, and Portuguese were reviewed and included. The age criteria of the population were determined according to the type of publication. For high-quality evidence articles (meta-analyses, systematic reviews, randomized studies, and cohorts), pediatric studies (age $<21$ years) were selected. For other observational studies (excluding cohorts), consensuses, and reviews, priority was given to pediatric studies, but adult literature was not excluded if no pediatric literature was found. Studies published from 2005 onward were included. Since this is a narrative review, the assessment of the included articles considered the authors' experience. A method of evidence assessment was not included in the review.

\section{Epidemiological aspects}

The most recent PARDS definition was published by the Pediatric Acute Lung Injury Consensus Conference (PALICC) in 2015'. That definition was validated by an international, multicenter, epidemiological study called PARDIE, published in 2019. To date, this study is the most comprehensive in terms of epidemiological data on PARDS $^{2}$. One hundred and forty-five centers in 27 countries participated for 10 non-consecutive weeks. A total of 744 patients with PARDS were identified; 708 were included. The study reported $3.2 \%$ of new cases of PARDS, with a mortality of $16 \%$. Patients with PARDS comprised $6.1 \%$ of all patients on mechanical ventilation. Mortality was $32.7 \%$ for patients with severe PARDS versus mild (12.4\%) and moderate (10.3\%) PARDS. Patients with severe PARDS had twice as many days with mechanical ventilation as those with mild or moderate PARDS.

Comorbidities are associated with some risk factors. Barreira et al. ${ }^{3}$ studied patients with chronic diseases, including respiratory pathologies $(26 \%)$, prematurity $(19.3 \%)$, gastrointestinal disorders (12.3\%), and genetic diseases (10.5\%). In this study, risk factors associated with mortality were multiple organ dysfunction syndrome, hypoxemia, and refractory shock. PARDS risk was high in such cases, with elevated scores on the PRISM pediatric mortality risk scale. These factors were analyzed in the study of mortality prediction models performed with data from the PARDIE study ${ }^{4}$.

\section{Etiology}

PARDS develops due to pulmonary (primary) or systemic (secondary) damage. According to the PARDIE study, the most common causes in pediatrics are pneumonia (mortality $12 \%$ ) and sepsis (mortality $30 \%$ ); trauma is a common cause in adolescents. Cases of immersion and non-septic shock represented $1 \%$ of the cases but high mortality (67\% and $60 \%$, respectively). In nosocomial etiologies, post-transfusion pulmonary reactions are common causes. Lung injury induced by uncontrolled mechanical ventilation is common. Therefore the understanding of its pathophysiology and management is of primary importance to avoid worsening lung injury.

\section{Pathophysiology}

PARDS is characterized by a succession of sequential inflammatory events that ultimately disrupt the alveolocapillary unit. The pathophysiology is complex and involves the stimulus nature, host response, and side effects of management ${ }^{5,6}$.

Three histopathological stages have been described: exudative phase, proliferative phase, and fibrotic phase. The time of onset and duration of each stage is variable, and there is evidence of phase overlap. In the exudative phase, the lung's response to the occurrence of a lesion is initiated by the alveolar macrophage. The M1 macrophage is activated by NF-KB and secretes potent inflammatory mediators, including tumor necrosis factor, various interleukins (IL), and chemotactic cytokines (CCL), generating destruction and apoptosis of pneumocytes 1 and 2, and the subsequent release of epithelial mediators. The alveoli fill with protein-rich edema, inactivating the surfactant. The endothelial barrier disintegrates, and migration of neutrophils and monocytes initiates. Neutrophils promote the destruction of the alveolar epithelium and also induce hyaline membrane formation. Disruption of the endothelial-alveolar membrane generates interstitial edema. Endothelial damage in capillaries promotes intravascular coagulation and microthrombosis formation.

The proliferative phase is mediated by M2 macrophages, which release pulmonary repair mediators, reestablish the pulmonary epithelium's cellular 


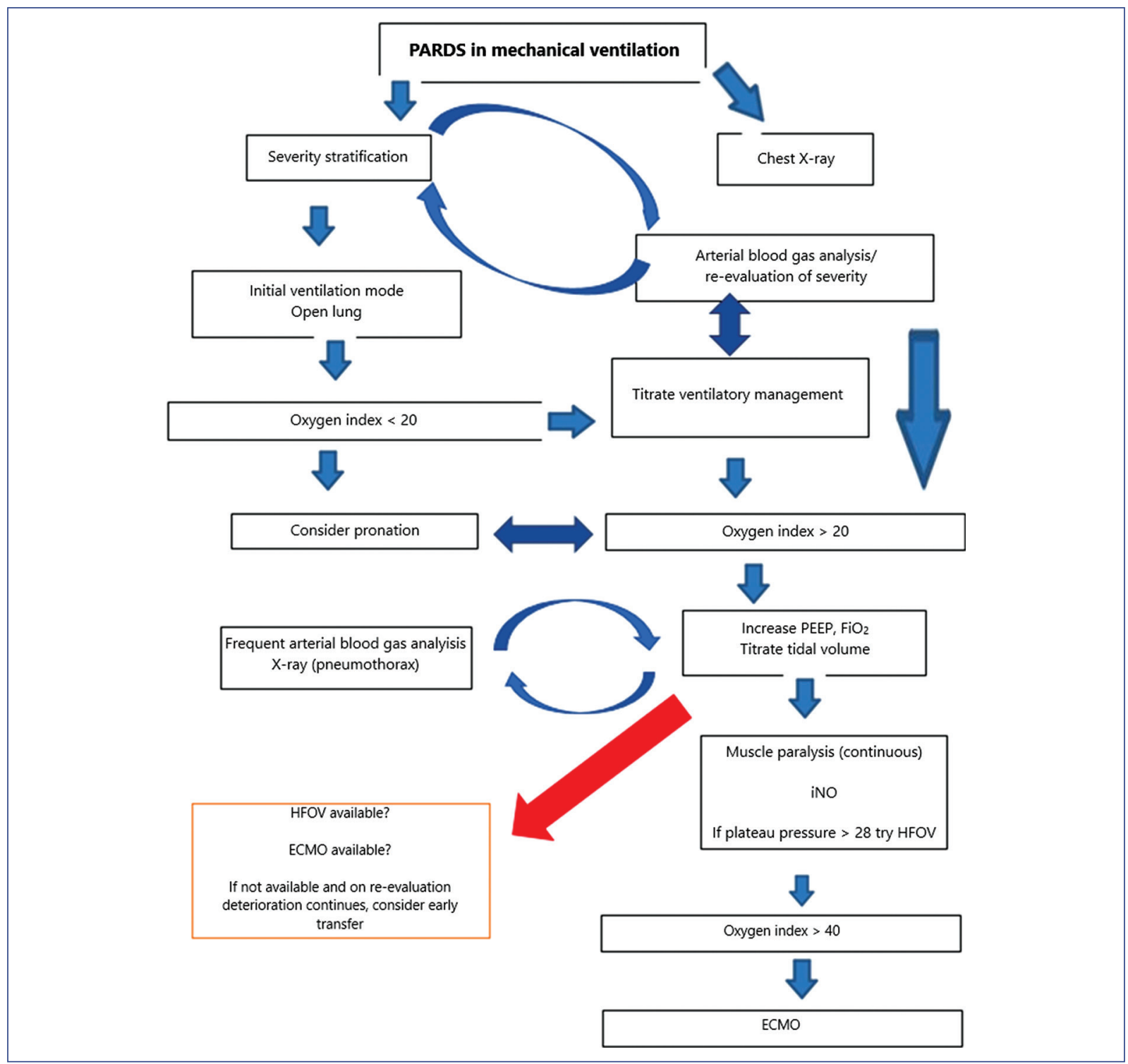

Figure 1. Management of pediatric acute respiratory distress syndrome (PARDS) in invasive mechanical ventilation (IMV). PEEP: positive end-expiratory pressure; FiO2: inspired fraction of oxygen; iNO: inhaled nitric oxide; HFOV: highfrequency oscillatory ventilation; ECMO: extracorporeal membrane oxygenation.

junctions, phagocyte apoptotic neutrophils, and facilitate the migration of bronchial progenitors and type 2 pneumocytes, which differentiate from type 1 pneumocytes and generate new surfactant. New membrane pumps help to drain the edema. The endothelial barrier is reestablished, and fibroblast proliferation favors the formation of a provisional matrix.

The fibrotic phase is the most destructive phase associated with mechanical ventilation and is characterized by permanent damage to the basement membrane. These changes do not allow alveolar epithelialization and result in persistent edema, intra-alveolar coagulation, collapse, and uncontrolled expression of M2 macrophages. The extracellular matrix develops interstitial and intra-alveolar fibrosis. The endothelium then undergoes a process of capillary obliteration and proliferation of fibroblasts and myofibroblasts.

Lung tissue damage is heterogeneous and leaves collapsed areas and alveolar units that preserve or lose gas exchange capacity. The "baby lung" theory states that in adult patients with ARDS, the lung portions that continued to have healthy tissue and where the gas exchange still occurs are equivalent to the volume of the lungs of pediatric patients aged 6-7 years. This 
theory was based on the portions of the lung that remained air filled and appeared normal on tomographic images. These intact lung spaces constitute a volume less than the corresponding for the patient's weight and size. This concept is fundamental when considering the tidal volumes to be used in PARDS. It is more relevant the tidal volume/"baby lung" ratio than the traditional tidal volume/kilogram of weight ${ }^{7}$. The process of mechanical ventilation-associated or mechanical ventilation-induced lung injury is part of the pathophysiological process of this disease. The physiological principle of this concept has been called mechanical power. This concept encompasses driving pressure, tidal volume, airflow, positive end-expiratory pressure (PEEP), and respiratory rate. This concept facilitates understanding the contribution of mechanical power to ventilator-associated lung injury ${ }^{8}$. Understanding these concepts help to avoid perpetuating lung injury and facilitate lung recovery ${ }^{9-11}$.

\section{Definition and diagnosis of PARDS}

The current definition of PARDS includes clinical criteria ${ }^{1}$. PARDS should be part of the diagnostic suspicion in patients presenting acute hypoxemic respiratory failure. Patients who require oxygen support are at risk of developing PARDS. The causes can be diverse, and the common manifestations are signs and symptoms caused by hypoxemia.

\section{Age of patients}

For the first time, the definition includes an age criterion for pediatric patients, unlike the Berlin definition. Patients with perinatal lung disease should be excluded. However, neonates who are hospitalized with respiratory failure unrelated to perinatal disease may present PARDS. Perinatal lung disease includes lung disease related to prematurity, perinatal lung injury (meconium aspiration, pneumonia, or neonatal sepsis), or other congenital abnormalities (such as a congenital diaphragmatic hernia or alveolar capillary dysplasia).

- Origin of edema. Respiratory failure cannot be fully explained by cardiac failure or fluid overload.

- Chronological criteria. Patients must present hypoxia, with radiographic changes, to be diagnosed with PARDS within 7 days of presenting a known clinical lesion. It is important to remember that this is an acute syndrome.

- Chest imaging studies. In chest imaging studies, the presence of new infiltrates is consistent with acute
Table 1. Oxygenation criteria according to PALICC definition Meet age and chronological requirements, the origin of edema,
and chest image

Non-invasive

mechanical

ventilation

Face mask,

BiPAP or CPAP

$\geq 5 \mathrm{cmH} 2 \mathrm{O}$

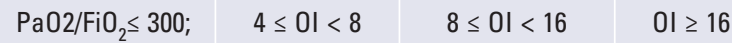

$\mathrm{SaO}^{\prime} / \mathrm{FiO}_{2} \leq 264 \quad 5 \leq \mathrm{OSI}<7.5 \quad 7.5 \leq \mathrm{OSI}<12.3 \quad \mathrm{OSI} \geq 12.3$

OI $=\mathrm{Pa} w \times \mathrm{FiO}_{2} \times 100 / \mathrm{PaO}_{2} ; \mathrm{OSI}=\mathrm{Pa} \mathrm{a} w \times \mathrm{FiO}_{2} \times 100 / \mathrm{SaO}_{2}$.

The $\mathrm{Ol}$ is defined as the ratio of the mean airway pressure ( $\mathrm{Pa} w, \mathrm{mmHg}$ ) multiplied by the inspired fraction of oxygen (FiO2) multiplied by 100 and divided by the partial pressure of oxygen in arterial blood ( $\mathrm{PaO2}$ ). It should be divided by oxygen saturation $\left(\mathrm{SaO}_{2}\right)$ to calculate OSI. OI should be used if arterial blood gases are available. Titrate FiO2 to obtain saturations $\leq 97 \%$ to use OSI.

BiPAP: bilevel positive airway pressure; CPAP: continuous positive airway pressure; OI: oxygen index; OSI: oxygen saturation index; PALICC: Pediatric Acute Lung Injury Consensus Conference.

parenchymal lung disease. There is no need for the infiltrates to be bilateral, unlike previous definitions.

- Oxygenation criteria. The definition is based on oxygenation criteria (Table 1). The PALICC definition proposes stratifying the severity of PARDS based on oxygenation index $(\mathrm{OI})$ or oxygen saturation index (OSI). The purpose of using oxygen saturation $\left(\mathrm{SpO}_{2}\right)$ is to avoid the exclusion of patients with PARDS who do not have an arterial blood gas report, which facilitates diagnosis and stratification in pediatric patients. $\mathrm{OI}$ is defined as the ratio of the mean airway pressure ( $\mathrm{Pa} w, \mathrm{mmHg}$ ) multiplied by the inspired fraction of oxygen $\left(\mathrm{FiO}_{2}\right)$, multiplied by 100 , and divided by the partial pressure of oxygen in arterial blood $\left(\mathrm{PaO}_{2}\right)$ : $\mathrm{OI}=\mathrm{Pa} w \times \mathrm{FiO}_{2} \times 100 / \mathrm{PaO}_{2}$. OSI is calculated by dividing by the arterial oxygen saturation $\left(\mathrm{SaO}_{2}\right)$ : $\mathrm{OSI}=\mathrm{Pa} w \times \mathrm{FiO}_{2} \times 100 / \mathrm{SaO}_{2}$. The inspired fraction of oxygen must be titrated to obtain saturations $\leq 97 \%$ to use OSI, while in patients in whom arterial blood gases are available, the Ol should be used (Table 1).

Furthermore, the oxygenation criteria include definitions for patients on non-invasive mechanical ventilation with continuous positive airway pressure $(\mathrm{CPAP}) \geq$ $5 \mathrm{cmH}_{2} \mathrm{O}$, in whom PARDS is defined with $\mathrm{PaO}_{2} / \mathrm{FiO}_{2}$ $\leq 300$ or $\mathrm{SaO}_{2} / \mathrm{FiO}_{2} \leq 264$.

\section{Special populations}

Cases of children with the left ventricular cardiac dysfunction, who meet the other PARDS criteria, should 
be diagnosed as such if hypoxemia is acute and new chest imaging changes cannot be explained by acute left ventricular heart failure or fluid overload ${ }^{3}$. In cyanotic heart disease cases, the same criteria are applied, as long as they have acute oxygenation impairment not explained by the heart disease.

In patients with chronic lung disease, the same criteria are used. The radiograph should show new infiltrates compared to the baseline radiograph and deterioration of oxygenation above the patient's standard requirement and meeting the oxygenation parameters described below.

\section{Patients at risk for PARDS}

One of the updates presented in the PALICC definitions was the inclusion of the diagnosis of patients at risk for PARDS. The criteria for age, chronology, edema origin, and chest imaging are the same as those already described in the primary definition; the difference occurs in the oxygenation criteria. The criterion for non-invasive mechanical ventilation patients on CPAP (continuous positive airway pressure) or bilevel positive airway pressure with a nasal mask is that $\mathrm{FiO}_{2} \geq 40 \%$ must maintain saturations of $88-97 \%$. For patients with an oxygen mask, nasal cannula, and high-flow nasal cannula, a minimum oxygen flow should be provided to maintain $88-97 \%$ oxygen saturation. The minimum flow is defined by age: $2 \mathrm{~L} / \mathrm{min}$ for < 1-year-old patients, $4 \mathrm{~L} / \mathrm{min}$ for patients aged 1-5 years, $6 \mathrm{~L} / \mathrm{min}$ for patients aged $5-10$ years, and $8 \mathrm{~L} /$ min for > 10-year-old patients.

For invasive mechanical ventilation, the criterion for patients at risk is oxygen supplementation necessary to maintain oxygen saturations $>88 \%$, but with $\mathrm{Ol}<4$ and $\mathrm{OSI}<5$.

\section{Differential diagnosis}

Several conditions associated with hypoxia are part of the differential diagnosis. These conditions require critical and urgent management and may include the following conditions:

- Interstitial or eosinophilic pneumonia.

- Obliterans bronchiolitis.

- Alveolar hemorrhage.

- Pneumonitis.

- Neurogenic, reperfusion, or high-altitude pulmonary edema.

- Pulmonary embolism.

- Neoplasm.

\section{Complementary tests}

- Arterial blood gas analysis.

- Inflammatory markers (routine use is not suggested).

- Chest X-ray. The definition does not require the use of an X-ray (it can be any chest image). It is fast, available in many places, can be portable, is inexpensive, has less radiation than CT scans, is easy to interpret, and does not require sedation ${ }^{12}$.

- Computed axial tomography, nuclear magnetic resonance, and ultrasound should be used when there is suspicion of an abscess, pleural effusions, persistent pneumothorax, pulmonary embolism, or vascular malformations.

- Echocardiogram (not routinely recommended). We strongly suggest considering it only to exclude pulmonary hypertension in patients with a history of prematurity ${ }^{13}$.

- Bronchoscopy and alveolar lavage. Not recommended unless fungal or pneumocystis pneumonia is suspected. Inflammatory markers in alveolar lavage are not routinely recommended ${ }^{14}$.

- Lung biopsy. Not recommended as a routine procedure $^{15}$.

\section{Principles of PARDS management}

The challenge is the identification of the population at risk and its immediate stratification. No specific treatment for the inflammatory process and alveolar-epithelial damage has been identified. The key to managing patients with PARDS is to treat the cause while lung tissue recovery occurs ${ }^{16}$.

Understanding these patients' ventilatory management has allowed intensivists to improve the survival rates among patients affected by this syndrome ${ }^{9}$. The key to management lies in not iatrogenically damage the lungs $s^{17,18}$. This concept is the most critical in the current management of PARDS. Mechanical ventilation is associated with different lung injuries, and parameters must be established to avoid these injuries' persistence and allow alveolar recovery ${ }^{10,11}$.

- Barotrauma: The pulmonary lesion is generated by elevated ventilatory pressures with peak and plateau pressures $>35 \mathrm{cmH}_{2} \mathrm{O}$, which generates disruption of the alveolar wall. These patients are at high risk of pneumothorax and emphysematous lesions, which reduce the gas exchange surface. Patients with air leak syndrome secondary to pneumothorax are very complex. 
- Volutrauma: It is the pulmonary lesion generated by high tidal volumes. The overdistension of the alveoli, according to the pulmonary area, would generate inflammation. The force it exerts on the different histological layers of the lungs generates an inflammatory cascade similar to that occurring in PARDS.

- Atelectrauma: Patients who have a low PEEP will lose alveolar recruitment. These patients will have alveoli that repeatedly collapse and distend, and this generates a loss of surfactant, which causes further collapse. As in volutrauma, the forced opening of collapsed alveoli will generate more inflammation.

\section{Mechanical ventilation}

The strategy and mode of ventilation can be chosen according to the medical team's expertise and ventilators' generation. The synchronized intermittent mandatory ventilation (SIMV) mode, with pressure control, offers certain advantages; however, no studies recommend only one mode ${ }^{19,20}$.

In any of the chosen modes, parameters should be used to maintain the concept of open lung ventilation ${ }^{11}$. It is suggested to use the open lung and permissive hypercapnia strategy to avoid overdistension of the lung, causing further damage $\mathrm{e}^{9,10}$. A pH of 7.15-7.30 can be used as a target, except in cases of elevated intracranial pressure, pulmonary hypertension, congenital heart disease, hemodynamic instability, and ventricular dysfunction. The principle of mechanical ventilation in PARDS is not to perpetuate lung damage but provide a lung-protective strategy (Fig. 1) 21 .

a) Endotracheal tube and ventilator circuit

An endotracheal tube cuff is recommended to avoid air leakage during invasive mechanical ventilation. Modern ventilators have compensation for air leakage. The cuff should be inflated to maintain $<10 \%$ air leakage and, if possible, with a manometer to avoid tracheal damage. It is suggested to perform recruitment maneuvers after each suction through the endotracheal tube in tidal volume loss. Also, to use closed suction circuits in PARDS.

b) Tidal volume and pressures

It is recommended to use an alveolar protective tidal volume (4-8 $\mathrm{mL} / \mathrm{kg}$ based on ideal body weight prediction) ${ }^{22}$. For patients with pressure-controlled ventilation (pressure control, $\mathrm{PC}$ ), it is essential to adjust the pressure and obtain a tidal volume between 4 and $8 \mathrm{~mL} / \mathrm{kg}$ to avoid barotrauma and volutrauma. Lung compliance or lung distensibility deteriorates in patients with PARDS. As controlled ventilatory parameters are increased, the risk of ventilator-induced lung injury (VILI) increases. It is suggested that the pressure difference (driving pressure $=$ plateau pressure - PEEP) should preferably not be $>15 \mathrm{cmH}_{2} \mathrm{O}$ in pressure-controlled or pressure-limited volume-controlled ventilation. It is recommended to limit the plateau pressure to 28-32 $\mathrm{cmH}_{2} \mathrm{O}$. The ventilator must be in the volumetric mode to calculate the plateau pressure. In patients with plateau pressure $>28 \mathrm{cmH}_{2} \mathrm{O}$ and moderate or severe PARDS, the use of high-frequency oscillatory ventilation (HFOV) should be considered. Also, $\mathrm{pH}$ and $\mathrm{pCO}_{2}$ should be monitored.

Tidal volume can be maintained between 6 and $8 / \mathrm{kg}$, although it can be lowered to 4 and $5 / \mathrm{kg}$ if there are no ventilatory problems to avoid volutrauma. The volume/ pressure curve should be carefully observed to determine the lower and upper inflection points and minimize alveolar recruitment loss. The objective of using this curve $(V / P)$ is to keep it in the maximum slope segment (low pressure for large volumes) and not at the extremes, between the lower inflection point (onset of recruitment) and the upper inflection point (deflection, the onset of overdistension). This part of the curve is where the lowest pressure difference (driving pressure) will be needed (Fig. 2).

c) PEEP and oxygen

The $\mathrm{FiO}_{2}$ should be adjusted according to the patient's needs and targets established according to the case's severity ${ }^{23}$. Oxygen supplementation should be adjusted to maintain $\mathrm{SaO}_{2}$ between $92 \%$ and $97 \%$, as long as PEEP is $<10 \mathrm{cmH}_{2} \mathrm{O}$. In severe PARDS, if PEEP is $>10$ $\mathrm{cmH}_{2} \mathrm{O}$, the goal is to maintain $\mathrm{SaO}_{2}$ between $88 \%$ and $92 \%$. This goal should be achieved with the lowest $\mathrm{FiO}_{2}$ possible since high values cause $\mathrm{O}_{2}$ toxicity. Regarding $\mathrm{PaO}_{2}$, we could consider acceptable values between 55 and $80 \mathrm{mmHg}$, as long as hemodynamic stability is maintained and hemoglobin $>7 \mathrm{~g} / \mathrm{dl}$.

Regarding PEEP, a range of $5-15 \mathrm{cmH}_{2} \mathrm{O}$ is recommended. According to the severity of PARDS, PEEP can increase, and the possibility of pulmonary overdistension and pneumothorax should be monitored, and the hemodynamic status of the patient as well. Regarding the lower inflection point on the volume/pressure curve used as a reference, the PEEP value should be at or above that point to avoid atelectasis and atelectrauma (Fig. 2). d) Time and inspiratory cycle

Increasing inspiratory time has a minor impact on the elevation of mean airway pressure. A ratio of 1:1 between inspiratory and expiratory times (I:E) can be maintained. The normal ratio is 1:2. I:E ratio of 1:1 does not appear to improve survival, although it may improve oxygenation. Reversing the I:E ratio is not recommended. 


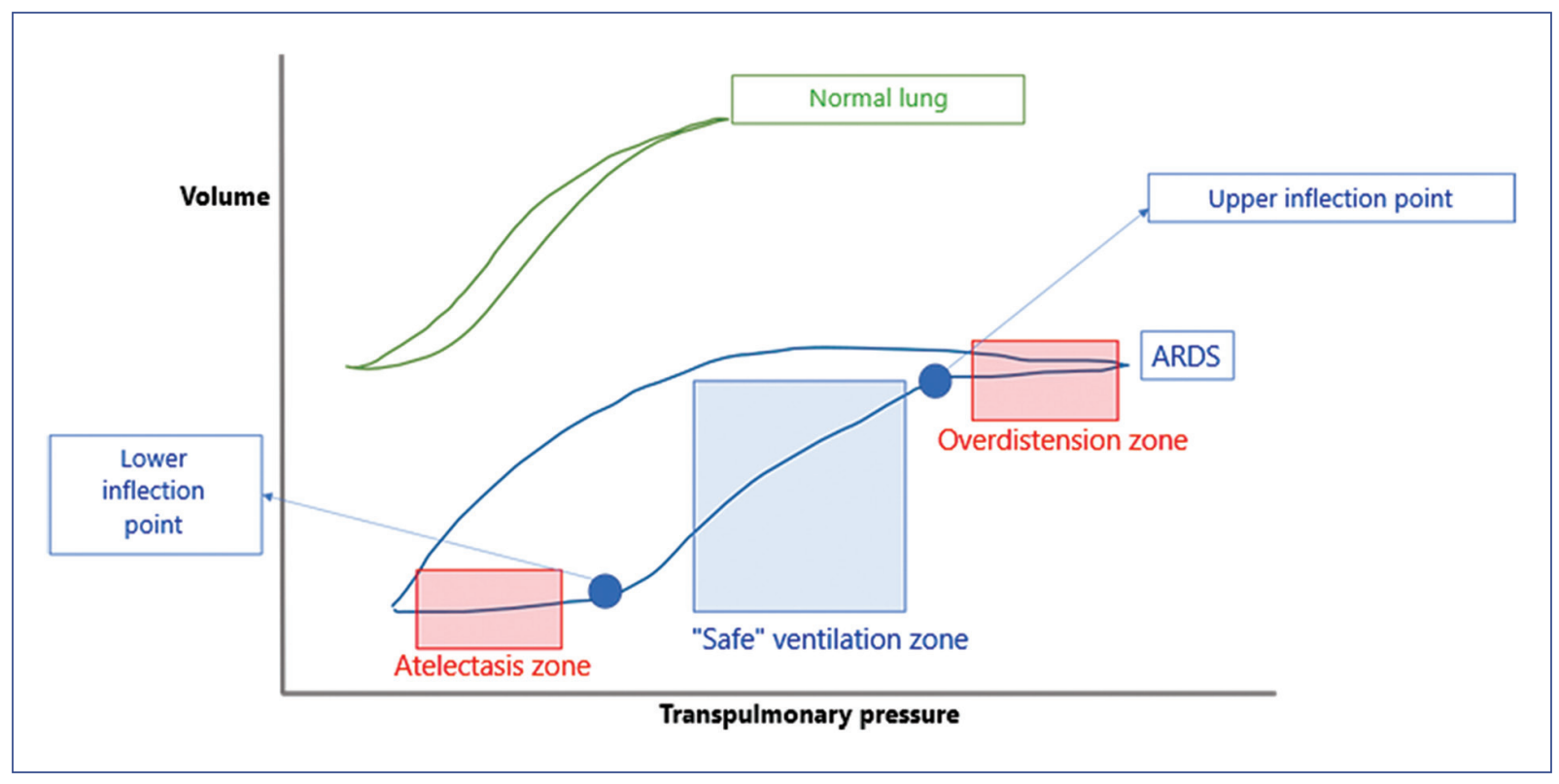

Figure 2. Volume/pressure curves in normal lung and acute respiratory distress syndrome (ARDS) lung. The safe ventilation zone is where no significant damage to the lungs is caused.

e) Recruitment maneuvers with hemodynamic status monitoring

It is recommended to maintain the patient's hemodynamic status at all times and avoid a shunt phenomenon. Preferably use a progressive recruitment strategy and assess the patient's condition comprehensively.

It is important to remember that these maneuvers are transitory and that studies have shown that they do not improve survival. They should only be used in patients who do not respond to other recruitment strategies and only if the response is favorable, without hemodynamic decompensation.

f) HFOV

A plateau pressure $>28 \mathrm{cmH}_{2} \mathrm{O}$ is recommended as a parameter to consider HFOV. Remember the negative impact on the right heart, which is one of the causes of significant morbidity and mortality in $\mathrm{HFOV}^{24,25}$. The usefulness of HFOV is unclear, but it is a rescue mode in severe cases, especially when the highest level of ventilation available is required. In a secondary analysis, HFOV is related to a longer time on ventilation in patients in whom it was initiated early. Clinically, one of the drawbacks of this mode of ventilation is the need for muscle paralysis.

g) Bilevel or airway pressure release ventilation (APRV)

Data regarding this mode of ventilation are limited. The evidence has been based on patient series, and there are medical groups that favor this ventilation method $^{26}$. A randomized study of APRV versus low tidal volume mode was discontinued after enrolling 52 patients, as it was associated with increased mortality. This method could be applied during the transition between conventional ventilation and HFOV or extracorporeal membrane oxygenation (ECMO), but its routine use is not recommended.

\section{Ventilation in a prone position}

The principal advantage of this method is its easy application in children ${ }^{27}$. The principle is that ventilation in prone position patients improves oxygenation; however, pediatric clinical studies do not demonstrate its usefulness when studying mortality as an outcome. Moreover, a Cochrane review published in 2012 concluded that the prone position improves oxygen saturation and arterial oxygen pressure, reduces hypoxemia events, and improves thoracoabdominal synchrony compared to the supine position ${ }^{28}$. These findings are similar to those reported in adults, in which whom its early use is recommended ${ }^{29,30}$. By improving recruitment in dependent areas, volutrauma and barotrauma could be minimized and hence the decrease of $\mathrm{FiO}_{2}{ }^{31}$.

Establishing patient care measures using a prone positioning strategy and verifying the endotracheal tube position to avoid unplanned extubation is essential. Also, to have a rotation protocol to avoid pressure ulcers, especially on the face. 
Since prone ventilation is an unproblematic measure, it can be used quickly to gain time and improve oxygenation. An early implementation may avoid escalation to other more invasive or unavailable therapies. During the coronavirus pandemic, adult intensivist teams recommended prone ventilation in non-intubated patients with high oxygen requirements to avoid early intubation ${ }^{32,33}$.

\section{ECMO}

This strategy may improve survival in PARDS patients with severe manifestations but high costs and severe possible side effects. The moment at which the patient should start this approach has not yet been determined. It is suggested to consider ECMO in patients in whom the open lung strategy fails ${ }^{34,35}$ and is recommended in patients with severe PARDS in which the cause is considered reversible. The introduction of percutaneous venous ECMO makes it easier to consider its use in pediatrics. It is postulated that a very high $\mathrm{OI}$ value (> 40 ) is one of the criteria for considering $\mathrm{ECMO}^{36}$; another criterion is the recurrence of pneumothorax.

\section{Other therapeutic approaches}

There is no specific pharmacological treatment for PARDS. Some therapeutic strategies are used even with unfavorable evidence. The management, especially in severe cases, includes all necessary measures to gain time. Considering that these therapies have a low level of evidence, they can be initiated if they have no major risks for the patient ${ }^{29,37,38}$.

a) Negative cumulative balance

Negative water balance is ideal in PARDS, as long as hemodynamic stability is preserved. The aim should be to achieve a negative balance between 48 and $72 \mathrm{~h}$. The internal environment and acid-base status management should not be forgotten; hypovolemia and poor perfusion should be avoided. This measure has low evidence ${ }^{39}$.

b) Sedation/analgesia and muscle relaxants

It is necessary to limit muscle relaxants to the minimum number of days possible. The harmful effect of the association of corticoids and muscle relaxants on the appearance of myopathy in the critical patient should always be remembered, which can make extubation more difficult ${ }^{40}$. Relaxation is important and necessary at the onset of ventilation to assess lung compliance and minimize any restrictive pattern. In patients in whom HFOV is used, muscle paralysis will be necessary. The time of opioid sedation and analgesia should always be minimized to avoid adverse effects such as tolerance, withdrawal, and delirium (high level of evidence $)^{41}$. Likewise, the paralysis time should be minimized to reduce the risk of myopathy (high level of evidence $)^{42}$.

c) Inhaled nitric oxide (iNO)

iNO has produced short-term physiological improvements in ventilation-perfusion adaptation and intrapulmonary shunt ${ }^{43,44}$. According to current evidence, it can be used in patients with severe PARDS. It is helpful in cases of pulmonary hypertension, but its routine use is not recommended for PARDS.

d) Corticosteroids

The routine use of corticosteroids is not recommended since there are no studies in pediatric patients, except for one pilot study. Data in adults are controversial. According to the protocol described by Meduri et al., some centers use it regularly; inhaled corticosteroids have been investigated in a pilot study in adults (2016), which showed improved oxygenation following their administration ${ }^{45,46}$. A pilot study on applying this therapy in pediatric patients is currently underway at the University of Texas in Houston.

e) Surfactant

Regarding exogenous surfactant, the evidence is insufficient to recommend its use. The principal study to demonstrate its use was interrupted due to futility criteria $^{47}$.

\section{Extubation and weaning from invasive mechanical ventilation}

Extubation should be initiated on reversal of the causes that precipitated the need for invasive mechanical ventilation (IMV) and the PARDS resolution. The PICU work plan and protocol for weaning from IMV should be followed.

\section{Prognosis}

As demonstrated in the PARDIE study, the mortality of severe cases is $32.7 \%$. Surviving patients have prolonged intensive care stays, especially patients with severe PARDS. The impact on long-term respiratory and pulmonary function has not been measured in large-scale prospective studies. The available information has been obtained from small series. These studies have followed patients for up to 12 years after discharge from hospitalization. Studies with larger populations are needed. The age of the patients limits 
pulmonary function tests. Patients requiring sedation and prolonged paralysis are at risk for withdrawal syndrome, delirium, and myositis requiring critical care. The impact on neurodevelopment in these patients has not been studied in detail. However, information on cognitive, emotional, social, and behavioral deficits from intensive care hospitalization is not specific for PARDS $^{48}$.

As PARDS is complex, physicians treating pediatric patients must be aware of management's new definitions and principles.

The primary approach to the management of PARDS is based on mechanical ventilation, with lung protective strategies. This mode of ventilation improves patient survival. The PARDS criteria and concepts are essential for any physician treating patients in pediatric critical care units.

It is necessary to know the equipment available in each center and recognize the transfer processes to advanced centers since the severe form of PARDS has a high mortality. Oxygenation compensation measures, such as prone ventilation, may help the patient before advanced critical care therapies.

\section{Ethical disclosures}

Protection of human and animal subjects. The authors declare that no experiments were performed on humans or animals for this study.

Confidentiality of data. The authors declare that they have followed the protocols of their work center on the publication of patient data.

Right to privacy and informed consent. The authors declare that no patient data appear in this article.

\section{Conflicts of interest}

The authors declare no conflicts of interest.

\section{Funding}

None.

\section{References}

1. Khemani RG, Smith LS, Zimmerman JJ, Erickson S, Pediatric Acute Lung Injury Consensus Conference G. Pediatric acute respiratory distress syndrome: definition, incidence, and epidemiology: proceedings from the Pediatric Acute Lung Injury Consensus Conference. Pediatr Crit Care Med. 2015;16:S23-40.

2. Khemani RG, Smith L, Lopez-Fernandez YM, Kwok J, Morzov R, Klein MJ, et al. Paediatric acute respiratory distress syndrome incidence and epidemiology (PARDIE): an international, observational study. Lancet Respir Med. 2019;7:115-28.
3. Barreira ER, Munoz GO, Cavalheiro PO, Suzuki AS, Degaspare NV, Shieh $\mathrm{HH}$, et al. Epidemiology and outcomes of acute respiratory distress syndrome in children according to the Berlin definition: a multicenter prospective study. Crit Care Med. 2015;43:947-53.

4. Yehya N, Harhay MO, Klein MJ, Shein SL, Pineres-Olave BE, Izquierdo L, et al. Predicting mortality in children with pediatric acute respiratory distress syndrome: a pediatric acute respiratory distress syndrome incidence and epidemiology study. Crit Care Med. 2020;48:e514-22.

5. Thompson BT, Chambers RC, Liu KD. Acute respiratory distress syndrome. N Engl J Med. 2017;377:562-72.

6. Sapru A, Flori H, Quasney MW, Dahmer MK, Pediatric Acute Lung Injury Consensus Conference G. Pathobiology of acute respiratory distress syndrome. Pediatr Crit Care Med. 2015;16:S6-22.

7. Gattinoni L, Pesenti A. The concept of "baby lung". Intensive Care Med. 2005;31:776-84.

8. Gattinoni L, Tonetti T, Cressoni M, Cadringher P, Herrmann P, Moerer O, et al. Ventilator-related causes of lung injury: the mechanical power. Intensive Care Med. 2016;42:1567-75.

9. Biehl M, Kashiouris MG, Gajic O. Ventilator-induced lung injury: minimizing its impact in patients with or at risk for ARDS. Respir Care. 2013; 58:927-34.

10. Curley GF, Laffey JG, Zhang H, Slutsky AS. Biotrauma and ventilator-induced lung injury: clinical implications. Chest. 2016;150:1109-17.

11. Amado-Rodríguez L, del Busto C, García-Prieto E, Albaiceta GM. Mechanical ventilation in acute respiratory distress syndrome: the open lung revisited. Med Intensiva. 2017;41:550-8.

12. Cressoni $M$, Cadringher $P$, Chiurazzi $C$, Amini M, Gallazzi E, Marino A, et al. Lung inhomogeneity in patients with acute respiratory distress syndrome. Am J Respir Crit Care Med. 2014;189:149-58.

13. Hopper RK, Abman SH, Ivy DD. Persistent challenges in pediatric pulmonary hypertension. Chest. 2016;150:226-36.

14. Grunwell JR, Giacalone VD, Stephenson S, Margaroli C, Dobosh BS Brown MR, et al. Neutrophil dysfunction in the airways of children with acute respiratory failure due to lower respiratory tract viral and bacterial coinfections. Sci Rep. 2019:9:1-13.

15. Forel JM, Guervilly C, Hraiech S, Voillet F, Thomas G, Somma C, et al. Type III procollagen is a reliable marker of ARDS-associated lung fibroproliferation. Intensive Care Med. 2015;41:1-11.

16. Cavalcanti AB, Suzumura EA, Laranjeira LN, Paisani DM, Damiani LP, Guimarães HP, et al. Effect of lung recruitment and titrated positive end-expiratory pressure (PEEP) vs. low peep on mortality in patients with acute respiratory distress syndrome: a randomized clinical trial. JAMA. 2017;318:1335-45.

17. Walkey AJ, Goligher EC, Del Sorbo L, Hodgson CL, Adhikari NK, Wunsch $\mathrm{H}$, et al. Low tidal volume versus non-volume-limited strategies for patients with acute respiratory distress syndrome. A systematic review and meta-analysis. Ann Am Thorac Soc. 2017;14:S271-9.

18. Walkey AJ, Del Sorbo L, Hodgson CL, Adhikari NK, Wunsch H, Meade MO, et al. Higher PEEP versus lower PEEP strategies for patients with acute respiratory distress syndrome. A systematic review and meta-analysis. Ann Am Thorac Soc. 2017;14:S297-303.

19. Essouri S, Carroll C, Pediatric Acute Lung Injury Consensus Conference G. Non-invasive support and ventilation for pediatric acute respiratory distress syndrome: proceedings from the Pediatric Acute Lung Injury Consensus Conference. Pediatr Crit Care Med. 2015;16:S102-10.

20. Farias JA, Fernandez A, Monteverde E, Flores JC, Baltodano A, Menchaca $A$, et al. Mechanical ventilation in pediatric intensive care units during the season for acute lower respiratory infection: a multicenter study. Pediatr Crit Care Med. 2012;13:158-64.

21. Kneyber MC, de Luca D, Calderini E, Jarreau PH, Javouhey $E$, Lopez-Herce J, et al. Recommendations for mechanical ventilation of critically ill children from the Paediatric Mechanical Ventilation Consensus Conference (PEMVECC). Intensive Care Med. 2017;43:1764-80.

22. Rimensberger PC, Cheifetz IM, Pediatric Acute Lung Injury Consensus Conference G. Ventilatory support in children with pediatric acute respiratory distress syndrome: proceedings from the Pediatric Acute Lung Injury Consensus Conference. Pediatr Crit Care Med. 2015;16:S51-60.

23. Britos M, Smoot E, Liu KD, Thompson BT, Checkley W, Brower RG, et al. The value of positive end-expiratory pressure and $\mathrm{FiO}_{2}$ criteria in the definition of the acute respiratory distress syndrome. Crit Care Med. 2011;39:2025-30.

24. Bateman ST, Borasino S, Asaro LA, Cheifetz IM, Diane S, Wypij D, et al. Early high-frequency oscillatory ventilation in pediatric acute respiratory failure. A propensity score analysis. Am J Respir Crit Care Med. 2016;193:495-503.

25. Lall $R$, Hamilton $P$, Young D, Hulme $C$, Hall $P$, Shah $S$, et al. A randomised controlled trial and cost-effectiveness analysis of high-frequency oscillatory ventilation against conventional artificial ventilation for adults with acute respiratory distress syndrome. The OSCAR (OSCillation in ARDS) study. Health Technol Assess. 2015;19:1-177.

26. Ganesan SL, Jayashree M, Singhi SC, Bansal A. Airway pressure release ventilation in pediatric acute respiratory distress syndrome. A randomized controlled trial. Am J Respir Crit Care Med. 2018;198:1199-207. 
27. Fineman LD, LaBrecque MA, Shih MC, Curley MA. Prone positioning can be safely performed in critically ill infants and children. Pediatr Crit Care Med. 2006;7:413-22.

28. Gillies $D$, Wells $D$, Bhandari AP. Positioning for acute respiratory distress in hospitalised infants and children. Cochrane Database Syst Rev. 2012;7:1-68.

29. Tamburro RF, Kneyber MC, Pediatric Acute Lung Injury Consensus Conference G. Pulmonary specific ancillary treatment for pediatric acute respiratory distress syndrome: proceedings from the Pediatric Acute Lung Injury Consensus Conference. Pediatr Crit Care Med. 2015;16:S61-72.

30. Curley MA, Hibberd PL, Fineman LD, Wypij D, Shih MC, Thompson JE, et al. Effect of prone positioning on clinical outcomes in children with acute lung injury randomized controlled trial. JAMA. 2005;294:229-37.

31. Sud S, Friedrich JO, Taccone P, Polli F, Adhikari NK, Latini R, et al. Prone ventilation reduces mortality in patients with acute respiratory failure and severe hypoxemia: systematic review and meta-analysis. Intensive Care Med. 2010;36:585-99.

32. Meng L, Qiu H, Wan L, Ai Y, Xue Z, Guo Q, et al. Intubation and ventilation amid the COVID-19 outbreak: Wuhan's experience. Anesthesiology. 2020;132:1317-32

33. Sorbello M, El-Boghdadly K, Di Giacinto I, Cataldo R, Esposito C, Falcetta S, et al. The Italian coronavirus disease 2019 outbreak: recommendations from clinical practice. Anaesthesia. 2020;75:724-32.

34. Barrett KA, Hawkins N, Fan E. Economic evaluation of venovenous extracorporeal membrane oxygenation for severe acute respiratory distress syndrome. Crit Care Med. 2019;47:186-93.

35. Crow S, Fischer AC, Schears RM. Extracorporeal life support: utilization, cost, controversy, and ethics of trying to save lives. Semin Cardiothorac Vasc Anesth. 2009;13:183-91.

36. Dalton HJ, Macrae DJ, Pediatric Acute Lung Injury Consensus Conference G. Extracorporeal support in children with pediatric acute respiratory distress syndrome: proceedings from the Pediatric Acute Lung Injury Consensus Conference. Pediatr Crit Care Med. 2015;16:S111-7.

37. Rowan CM, Klein MJ, Hsing DD, Dahmer MK, Spinella PC, Emeriaud G et al. Early use of adjunctive therapies for pediatric acute respiratory distress syndrome: a PARDIE study. Am J Respir Crit Care Med. 2020;201:1389-97.

38. Valentine SL, Nadkarni VM, Curley MA, Pediatric Acute Lung Injury Consensus Conference G. Nonpulmonary treatments for pediatric acute respiratory distress syndrome: Proceedings From The Pediatric Acute Lung Injury Consensus Conference. Pediatr Crit Care Med. 2015;16:S73-85.
39. Flori HR, Church G, Liu KD, Gildengorin G, Matthay MA. Positive fluid balance is associated with higher mortality and prolonged mechanical ventilation in pediatric patients with acute lung injury. Crit Care Res Pract. 2011:2011:1-5.

40. Chan KS, Mourtzakis M, Friedman LA, Dinglas VD, Hough CL, Ely EW, et al. Evaluating muscle mass in survivors of acute respiratory distress syndrome: a 1-year multicenter longitudinal study. Crit Care Med. 2018;46:1238-46.

41. National Heart, Lung, and Blood Institute PETAL Clinical Trials Network; Moss M, Huang DT, Brower RG, Ferguson ND, et al. Early neuromuscular blockade in the acute respiratory distress syndrome. $\mathrm{N}$ Engl $\mathrm{J}$ Med. 2019;380:1997-2008.

42. Needham CJ, Brindley PG. Best evidence in critical care medicine: the role of neuromuscular blocking drugs in early severe acute respiratory distress syndrome. Can J Anaesth. 2012;59:105-8.

43. Gebistorf F, Karam O, Wetterslev J, Afshari A. Inhaled nitric oxide for acute respiratory distress syndrome (ARDS) in children and adults. Cochrane Database Syst Rev. 2018;12:1-77.

44. Ruan SY, Huang TM, Wu HY, Wu HD, Yu CJ, Lai MS. Inhaled nitric oxide therapy and risk of renal dysfunction: a systematic review and meta-analysis of randomized trials. Crit Care. 2015;19:1-10.

45. Drago BB, Kimura D, Rovnaghi CR, Schwingshackl A, Rayburn M, Meduri GU, et al. Double-blind, placebo-controlled pilot randomized trial of methylprednisolone infusion in pediatric acute respiratory distress syndrome. Pediatr Crit Care Med. 2015;16:e74-81.

46. Meduri GU, Bridges L, Shih MC, Marik PE, Siemieniuk RA, Kocak M. Prolonged glucocorticoid treatment is associated with improved ARDS outcomes: analysis of individual patients' data from four randomized trials and trial-level meta-analysis of the updated literature. Intensive Care Med. 2016;42:829-40.

47. Willson DF, Thomas NJ, Markovitz BP, Bauman LA, DiCarlo JV, Pon S, et al. Effect of exogenous surfactant (calfactant) in pediatric acute lung injury: a randomized controlled trial. JAMA. 2005;293:470-6.

48. Quasney MW, Lopez-Fernandez YM, Santschi M, Watson RS, Pediatric Acute Lung Injury Consensus Conference $\mathrm{G}$. The outcomes of children with pediatric acute respiratory distress syndrome: Proceedings From The Pediatric Acute Lung Injury Consensus Conference. Pediatr Crit Care Med. 2015;16:S118-31 